\title{
Effects of repeated defeat by a dominant conspecific on subsequent pain sensitivity, open-field activity, and escape learning
}

\author{
JON L. WILLIAMS and DEAN M. LIERLE \\ Kenyon College, Gambier, Ohio
}

\begin{abstract}
Male rats were tested as intruders for 25 consecutive days in colonies that had either aggressive (i.e., alpha) or nonaggressive conspecific residents. Alpha-defeated intruders, in contrast to nondefeated rats, showed more defensive behavior, less gain in body weight, and received more bites during the course of these sessions. Tail-flick tests, using a heat source, revealed that both groups of intruders showed comparable sensitivity/reactivity to pain, and there was no evidence of analgesia as a function of resident encounters. Immediately after the last intruder session, all subjects were tested for exploratory activity in an open-field apparatus with the odors (i.e., soiled bedding) from the alpha colonies present. Defeated intruders showed significantly less locomotion, in terms of the number of grid crossings, than nondefeated rats. Twenty-four hours later, randomly selected subgroups of defeated and nondefeated subjects were briefly exposed, without being defeated, to aggressive colonies, and all rats were then retested for activity with alpha odors present. Previously defeated intruders were again less active, and the colony exposure treatment suppressed the activity of defeated, but not nondefeated, subjects. Finally, $24 \mathrm{~h}$ after another resident-intruder session, both groups of intruders showed comparable FR 1 escape performance in a shuttlebox with alpha odors present, but the defeated rats failed to learn a subsequent FR 2 escape task. The findings of this experiment are discussed in terms of the concept of "learned helplessness," the effects of ethological stressors, and the authors' stress-coping-fear-defense (SCFD) theory.
\end{abstract}

Numerous investigators have shown that repeated exposure to a laboratory stressor, such as electric shock, produces alterations in behavioral and neurophysiological processes. In mice and rats, experiencing inescapable shock has been shown to interfere with the subsequent acquisition of escape responses (e.g., Anisman, Suissa, \& Sklar, 1980), discrimination learning (Jackson, Alexander, \& Maier, 1980), and appetitive operants (e.g., Rosellini, 1978; Rosellini, DeCola, \& Shapiro, 1982). Transituational deficits produced by inescapable shock have also been found in tests of nonassociative or unlearned responses, such as nonreinforced shuttlebox running (Maier, Coon, McDaniel, Jackson, \& Grau, 1979), shock-elicited fighting (Maier, Anderson, \& Lieberman, 1972), general activity (Drugan \& Maier, 1982), and specific forms of exploratory behavior (e.g., Bruto \& Anisman, 1983). In addition, inescapable shock has been found to result in opioid- and nonopioid-mediated analgesia to nociceptive stimuli (see Maier et al., 1983, for a review of this literature), and to induce increases in corticosteroids and acetylcholine and decreases in norepinephrine, dopamine, and serotonin (e.g., Anisman,

This research was supported by USPHS Research Grant 1RO1NH43815-01. The authors wish to thank Arthur Lecesse and Duncan White for their helpful comments. Reprint requests should be sent to Jon L. Williams, Department of Psychology, Kenyon College, Gambier, OH 43022.
Kokkinidis, \& Sklar, 1982; Weiss et al., 1981). Since these effects typically do not follow experience with equal amounts of escapable shock, or controllable stress, they have been referred to as "learned-helplessness" effects (Maier \& Seligman, 1976).

Much of the current research in our laboratory has utilized the traditional helplessness procedures in order to increase our understanding of how various shock manipulations alter species-typical behaviors. For example, dominant colony male rats given inescapable, but not escapable, shock show an increase in defensive responding and virtually no aggression or offensive behavior when later tested with naive conspecific intruders (Williams, 1982). In addition, we have shown that rats that receive inescapable shock later display an enhanced series of defensive or submissive behaviors when tested as intruders in colonies with male residents that were previously known to be aggressive (Williams \& Lierle, 1986). Both of these stress-induced changes in agonistic behavior can be prevented or reversed by administering a session of escapable shock prior to (i.e., immunization) or after (i.e., therapy) the exposure to inescapable shock (Williams \& Lierle, 1986). Enhanced defensive behavior in response to inescapable, but not escapable, shock has also been shown to disrupt normal maternal responses of lactating rats (Williams, 1984), again demonstrating learnedhelplessness effects with species-typical behaviors. 
Recently, Williams (1987a, 1987b; Williams \& Lierle, 1986) interpreted the previously described disruptions of learned and species-typical responses in terms of a model that is referred to as the stress-coping-fear-defense (SCFD) theory. Briefly, this theory assumes that exposure to inescapable, as opposed to escapable, shock produces greater fear conditioning to contextual or environmental cues (Desiderato \& Newman, 1971; Mineka, Cook, \& Miller, 1984). This theory also postulates that the presence of contextual stimuli associated with uncontrollable stress will subsequently result in the occurrence of defensive behaviors to the exclusion of other learned and unlearned responses. The major assumptions of the SCFD theory were recently tested by examining the influence of shock controllability and conspecific stress odors on defensive burying and freezing behaviors following a single shock from a prod in a chamber that contained movable bedding material (Williams, 1987b). Specifically, rats were given either inescapable shocks or no shocks and were tested $24 \mathrm{~h}$ later, with urine and feces from either shocked or nonshocked donor rats added to the bedding material of the test chamber. Preshocked subjects spent less time burying the shock prod and displayed more freezing than nonshocked subjects. The differences in burying and freezing between the shocked and nonshocked groups of rats was significantly augmented when the subjects were tested in the presence of odors from stressed, as opposed to nonstressed, donors. In a second experiment, it was determined that inescapable, in contrast to escapable, shock was necessary to produce a decrease in burying and an increase in freezing when conspecific stress odors were present during testing. These findings clearly indicate that uncontrollable stress experience, in combination with later exposure to conspecific odors associated with the stress situation, produces freezing as the dominant form of defensive behavior with a suppression of other responses that involve overt activity (e.g., flight) and/or interaction with the bedding material (e.g., prod burying, burrowing). On the basis of these and other findings (e.g., Minor \& Lolordo, 1984), we believe that the behavioral and physiological disruptions (learned-helplessness effects) result from the greater fear elicited by the inadvertent presence, in the test situation, of stress odors that activate defense and submission systems (e.g., Adams, 1980).

If repeated exposure to inescapable electric shock results in a fear-motivated state that enhances defense and learned-helplessness symptoms, then more natural, or ethological, types of stressors might be expected to produce similar effects. In both rats and mice, repeated defeat experienced by an intruder in a colony of conspecifics with an aggressive or dominant male has been shown to produce a series of behavioral and physiological consequences that resemble the effects of inescapable shock. For example, repeated defeat by dominant resident conspecifics results in both a decrease in offensive aggression (e.g., Kahn, 1951; Lagerspetz \& Sandnabba, 1982; Seward, 1946) and in increase in defensive responses (e.g., Frischknecht, Siegfried, \& Waser, 1982;
Kulling, Frischknecht, Pasi, Waser, \& Siegfried, 1987) in subsequent agonistic encounters. This type of natural stressor also decreases subsequent exploratory behavior and increases freezing (e.g., Raab et al., 1986). Finally, repeated defeat by conspecifics produces many of the physiological changes that also occur as a result of shockinduced learned helplessness, such as weight loss (e.g., Adams \& Boice, 1983; Luciano \& Lore, 1975; Thor \& Flannelly, 1976; Raab et al., 1986), endocrine changes (e.g., Raab et al., 1986), and analgesia that is mediated by endogenous opioid mechanisms (e.g., Miczek, Thompson, \& Shuster, 1982, 1986; Rodgers \& Randall, 1986b) and nonopioid mechanisms (McAllister, Berry, \& Brain, 1985; Rodgers \& Randall, 1986a).

The major purpose of the present study was to compare the consequences of a colony intruder's exposure to repeated conspecific defeat with the effects typically produced by inescapable shock. During the stressinduction phase of this experiment, rats were tested for 25 consecutive days as intruders in colonies that had either very aggressive (i.e., a dominant or alpha male) or nonaggressive residents. During these sessions, the number of bites made by the colony residents, the cumulative duration of defensive behavior, and the weight loss shown by the intruders were recorded. In addition, tail-flick tests of baseline and postdefeat analgesia in both groups of intruders were conducted. Immediately following the last resident-intruder session, activity in a open-field apparatus was tested. On the following day, a second activity test was conducted, with half of the subjects in each group receiving a brief exposure, without being bitten, to an aggressive colony before being placed in the open-field apparatus. Finally, after another session of defeat or nondefeat in their respective colonies, each subject was tested for escape learning in a shuttlebox apparatus, with the traditional learned-helplessness procedure of a block of single-crossing escape responses, followed by a series of double-crossing responses. On the basis of the findings of our previous research on the effects of prior shock and the presence of conspecific stress odors during tests of defensive burying (Williams, 1987b), we decided that the odors of the alpha rats should be present during all analgesia, activity, and shuttlebox-learning tests. In our lab, the presence of alpha odors during testing had recently been found to be a critical factor in the mediation of defeatinduced fear, as evidenced by a subsequent increment in freezing and a suppression in defensive prod-shock burying (Williams \& Scott, 1988).

\section{METHOD}

\section{Subjects}

Twenty-four male albino rats of Holtzman descent, weighing $375-425 \mathrm{~g}$ at the start of the experiment, served as subjects. They were maintained on a 12:12-h reverse light:dark cycle, and had food and water continuously available in their individual cages. In addition, 12 colonies of 1-year-old male rats of Holtzman descent were used for resident-intruder testing. It had previously been established, during a series of 10 consecutive daily resident-intruder tests, that 
these colonies had dominant residents that displayed asymptotic levels of aggressive responses (e.g., piloerection, lateral attacks, and biting). Each of these aggressive colonies contained 1 female (120-150 days old) and 2 males that had been residents in a particular colony cage for a period of 60-70 days. The alpha males were $526-568 \mathrm{~g}$ at the time of intruder testing. Another 12 colonies of rats that were approximately the same age and weight as the animals in the alpha colonies, and that consistently displayed no signs of aggression, were used to provide exposure to male conspecifics, per se, without defeat experience. The light:dark cycle for the colonies was the same as that used for the intruder subjects, and the colonies had free access to food and water.

\section{Apparatus}

The 12 aggressive and nonaggresive colonies were each housed in $50 \times 40 \times 20 \mathrm{~cm}$ polypropylene tubs with stainless steel wire tops. The floors of the colony cages were covered with ground corncob mash, bedding material that was changed periodically but not immediately prior to or during the colony tests.

Observations and recordings during resident-intruder tests were made in a sound-attenuated experimental room. The animals could be seen through the wire covers of the colony cages. The colony area was illuminated by a $25-\mathrm{W}$ incandescent red bulb (G.E., $120 \mathrm{~V}$ ). The intruder animal was marked with a colored marker to facilitate identification. Electronic digital timers were used to record the duration of defensive responses shown by the intruders.

Pain sensitivity/reactivity, as an index of analgesia, was measured by the tail-flick latency to a heated coil that was located beneath a platform on which a tube-restraining device could be placed. The tube, which was made of Plexiglas, and was $28 \mathrm{~cm}$ in length and $7 \mathrm{~cm}$ in diameter. A glass jar, $7 \mathrm{~cm}$ in length $\times 6.5 \mathrm{~cm}$ in diameter, with a perforated metal top, was inserted into the tube. The rat was restrained in the remaining $21 \mathrm{~cm}$ of the tube by a gate that could be closed at the end of the tube. At the start of a trial, the rat's tail was extended outside of the tube and positioned along a marked groove that bisected a $2 \times 1 \mathrm{~cm}$ slot in the platform, exposing the electric coil to the midsection of the tail. Once the coil had been turned on, the latency of the tail's lateral deflections that occurred beyond the area of this slot was recorded by a digital stopwatch.

Exploratory activity was measured in a $75 \times 75 \times 30 \mathrm{~cm}$ openfield chamber that was divided into a $2 \times 2$ matrix of four squares marked on the floor. The chamber was made of plywood that was painted gray, and the frame top was covered with a $1-\mathrm{cm}-\mathrm{ga}$ hardware cloth. The open-field chamber was located in a separate room, illuminated with a $20-\mathrm{W}$ ceiling light, in which white background noise (75 dB SPL) was continuously presented.

Shock-escape testing was conducted in a shuttlebox (manufactured by BRS/LVE), measuring $45 \times 20 \times 20 \mathrm{~cm}$. The center of the shuttlebox contained a metal divider with a rounded archway, $8 \mathrm{~cm}$ wide and adjusted to $6.5 \mathrm{~cm}$ high. This height required the rat to crouch slightly to run through the archway from one side of the shuttlebox to the other. This apparatus was located inside a large experimental chamber that was illuminated by a 5-W light; white noise ( $75 \mathrm{~dB}$ SPL) was presented by a small speaker located in the middle of the ceiling of the chamber. Electric shock was delivered to the rat from the grid floor of the shuttlebox by means of a Lafayette 82400 shocker that was connected to a BRS/LVE grid scrambler. All testing contingencies were electronically controlled, and the latencies of the escape responses were automatically recorded by an electronic printout timer.

\section{Procedure}

The 24 rats to be used as subjects were assigned to one of two groups, matched on the basis of their body weight. All test sessions were conducted during the dark phase of the light:dark cycle. On the initial day of the experiment, the subjects in each group were weighed and given baseline tests of pain sensitivity/reactivity, using the tail-flick apparatus. For all subjects, the glass jar in the restraining tube was first filled with soiled bedding material from colony tubs of the alpha rats, thus exposing the subjects to alpha odors. After each subject was placed inside the tube, the gate at the end of the tube was closed and fastened. The rat's tail was then pulled outside the tube and positioned along the groove that marked the middle of the slot that exposed the electric heating coil. Three tail-flick test trials, separated by an intertrial interval of approximately $1 \mathrm{~min}$, were conducted while the rat was restrained. A trial was initiated by the simultaneous activation of the coil switch and the manual starting of the digital stopwatch. The heat from the coil radiated through the open slot in the platform, providing nociceptive stimulation on a spot about halfway between the base and the tip of the rat's tail. A trial was terminated when a lateral deflection of the tail beyond the area of the slot occurred. The response latency was monitored by means of a stopwatch. Trials were automatically terminated if a tail flick had not occurred in $10 \mathrm{sec}$.

On the following day, subjects in the defeated intruder (DI) group were individually tested for $15 \mathrm{~min}$ as resident intruders in one of the 12 aggressive colonies. During these tests, the female rat in the colony was removed and food and water were not available. An experienced observer of agonistic behavior recorded the total defeat time displayed by the intruder, as well as the number of bites it received. The defeat-time score obtained for each intruder was the total time during which the subject was engaged in either defensive rearing or lying on its back, often combined with freezing. Bites were recorded only if they elicited an audible response by the intruder. Prior checks on the reliability of this scoring system, using videotapes of tests, have yielded correlations higher than .90 . The subjects in the nondefeated intruder (NI) group were given resident-intruder tests, using the previously described procedure, but they were placed in one of 12 colonies that previously had been observed to show no aggression. If any signs of aggression by a male in these colonies were noted, that male was replaced during subsequent tests by another male that was known to be nonaggressive. Resident-intruder tests were given for 25 consecutive days in the aggressive and nonaggressive colony cages for the DI and NI groups, respectively. The specific colony that each intruder encountered was determined on a rotational basis for each group. Immediately after the resident-intruder test on Days 12 and 24, each rat was tested for analgesia using the previously described tail-flick procedure.

Following the resident-intruder session on Day 25, all subjects were tested for exploratory activity, with some of the soiled bedding from the cages of the alpha colonies evenly distributed on the floor of the open-field apparatus. Locomotion was assessed for $10 \mathrm{~min}$ by recording the number of squares entered by the animal, the criterion being that the rear legs and the base of the tail be within a square. Each rat was tested in the same apparatus $24 \mathrm{~h}$ later with the soiled bedding of the alpha animals again present. Immediately before this activity test, half of the subjects in the defeated and nondefeated groups were given a 45-sec exposure (i.e., Groups DI-E and NI-E) to an alpha colony. Because this exposure was brief, the alpha rats exhibited aggressive behaviors (i.e., piloerection and lateral attacks), but did not bite. The remaining subgroups of rats (i.e., Groups DI-NE and NI-NE) were not exposed to the alpha colony residents before the activity test. The procedure for monitoring locomotion during this test was identical to that employed during the previous activity test.

On Day 27, the rats were given a final resident-intruder session in an aggressive or a nonaggressive colony. Twenty-four hours later, all subjects were given $\mathbf{3 0}$ trials of shock-escape training in the shuttlebox, with soiled bedding from the alpha colony rats distributed evenly in the aluminum tray beneath the grid floor. Each trial involved the presentation of an unsignaled .6-mA scrambled shock through the floor grids. If the rat completed the escape-response requirement, the shock was terminated; otherwise, shock termina- 
tion occurred automatically after $30 \mathrm{sec}$, and this value was entered as the cutoff response latency for that trial. The intertrial interval was a mean of $60 \mathrm{sec}$, with a range of 5 to $270 \mathrm{sec}$. A single crossing of the shuttlebox (FR 1) was required for escape on the first 5 trials. Two crossings of the shuttlebox (FR 2) were required for escape on the remaining 25 trials. The 5 FR 1 trials were used because control subjects in learned-helplessness experiments often do not learn FR 2 shuttling if it is not preceded by FR 1 shuttling (Maier \& Jackson, 1979). In addition, these trials function as priming stimuli to reinstate the effects of the prior experience with stress (Jackson, Maier, \& Coon, 1979).

\section{RESULTS}

In every test session, all the alpha residents defeated the colony intruders by displaying piloerection, followed by a series of lateral attacks. This offensive pattern typically resulted in the resident's biting the intruder several times and, between bites, pinning the intruder. In reaction to the alpha rat's aggressive responses, after the initial bite, the intruder showed the following defensive responses: lying on its back, standing upright with its back in the corner, and/or freezing with a crouched, submissive posture. During some of the initial resident-intruder tests, several intruder subjects would flee from the alpha male. However, this behavior, which usually resulted in the resident's biting the intruder, was not observed during subsequent test sessions. In contrast, the male residents in the nonaggressive colonies showed virtually no offensive postures and did not bite the intruders. Furthermore, the intruder subjects in these colonies did not display any defensive or submissive behaviors during the entire series of resident-intruder tests.

Figure 1 presents the mean number of bites received by each of the intruders and the mean defeat time, or the cumulative minutes they engaged in defensive behavior, for successive blocks of five resident-intruder test sessions. It is apparent that repeated exposures to defeat resulted in an increase in both of these measures. These results were confirmed by two independent, repeated measures analyses of variance (ANOVAs). The differences in the number of bites that the intruders received across the successive blocks of sessions were significant $[F(4,44)=5.20, p<.01]$. Subsequent post hoc, Newman-Keuls tests revealed that Block 1 differed significantly from Blocks 4 and $5(p<.01)$, with the latter two blocks not differeing from each other. In addition, Block 1 differed significantly $(p<.05)$ from Block 3 . Across blocks of repeated sessions, a significant increase in the defeat time shown by the intruders was also confirmed statistically $[F(4,44)=10.60, p<.01]$. Newman-Keuls tests indicated that Blocks 1,2 , and 3 differed significantly $(p<.01)$ from Blocks 4 and 5 , but there were no significant differences between the pairs of blocks within these two clusters.

At the start of the experiment, both the defeated (Group DI) and the nondefeated (Group NI) intruders were matched in terms of their body weights (i.e., both groups had a mean of $445 \mathrm{~g}$ ). Although all the rats showed

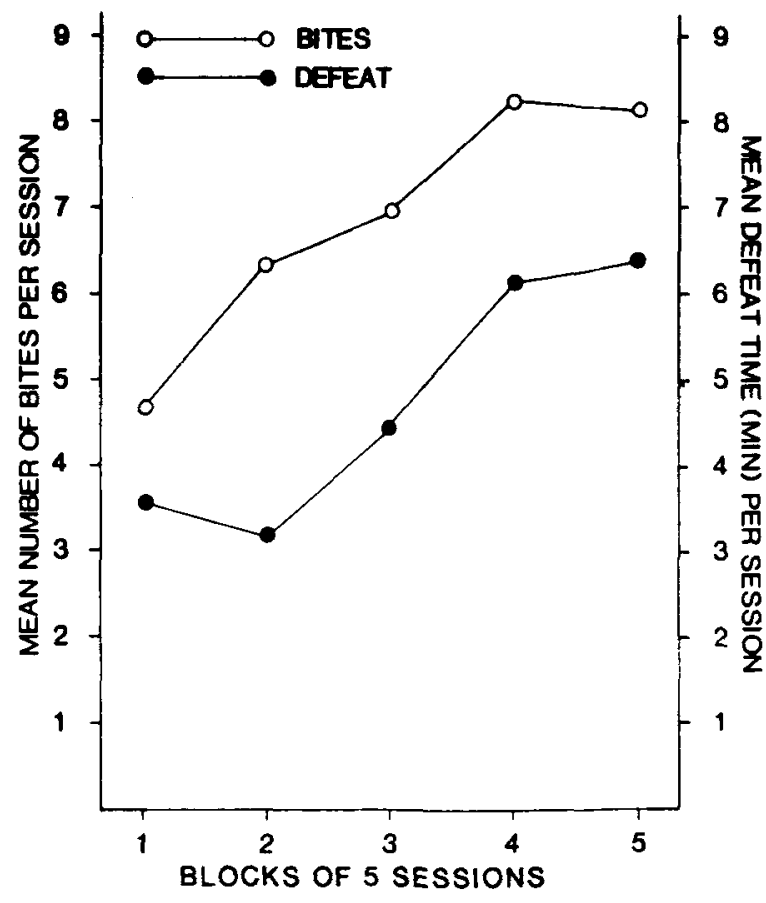

Figure 1. Mean number of bites received by intruders (left axis) and mean total duration of defensive responses, or defeat time (right axis), shown by defeated intruders across blocks of five resident-intruder sessions with aggressive colony residents.

an increase in weight during the 25 days of resident-intruder sessions, Group DI weighed significantly less than Group NI by the end of this period $[t(22)=2.48$, $p<.01$, one-tailed test], with mean weights of $463.80 \mathrm{~g}$ and $500.1 \mathrm{~g}$, respectively.

Statistical analyses of the results of the tail-flick tests of analgesia revealed that Groups DI and NI had baseline latencies that were not significantly different at the .05 level, with means of 4.77 and $5.26 \mathrm{sec}$, respectively. Further analyses indicated that there were no significant changes between or within these groups across the two subsequent tests administered immediately following resident-intruder tests given on Days 12 and 24 . The mean tail-flick latencies on these two tests were 4.48 and $4.73 \mathrm{sec}$, respectively, for Group DI, and 5.02 and $4.17 \mathrm{sec}$, respectively, for Group NI. Thus, there was no appareant evidence for an analgesic effect in either of the groups with repeated resident-intruder tests.

Figure 2 presents the mean number of crossings perminute, as a measure of exploratory activity or locomotion, for the defeated and nondefeated groups immediately after they were given the resident-intruder test on Day 25 . Both groups of intruders showed a gradual decline in activity over the 10-min test, and the defeated intruders were clearly less active than the nondefeated intruders throughout the entire test period. These observations were statistically supported by the results of a two-way, mixed-design ANOVA with groups $[F(1,22)=110.86, p<.001]$ and blocks $[F(4,88)=13.75, p<.001]$ being significant. Newman-Keuls tests revealed that there were significant 
decreases in activity between Blocks 1 and 2 for Group NI $(p<.01)$ and Group DI $(p<.05)$, but no significant within-group changes for the remaining blocks. Finally, across all five blocks, Group DI showed significantly less activity than Group NI (all $p s<.01$ ), with the former group showing considerably more freezing in the corners of the open-field apparatus.

A second activity test was conducted $24 \mathrm{~h}$ after the previous test in the same open-field apparatus. Figure 3 presents the mean number of crossings per minute for the defeated and the nondefeated intruders that were either briefly exposed to an alpha colony or not given such an exposure prior to the 10-min test. As found on the previous test, all groups showed a gradual decline in locomotion across the successive blocks of trials, and the defeated intruders were less active than the nondefeated intruders. Finally, it can be seen that subjects' prior exposure to alpha colonies, as opposed to nonexposure, resulted in a suppression of activity only for subjects that had previosuly experienced defeat by alpha-colony males. All of these results are confirmed by a three-way, mixeddesign ANOVA that reveals the following effects to be significant: groups $[F(1,22)=225.00, p<.001]$, exposure to a colony $[F(1,22)=13.48, p<.01]$, groups $\times$ exposure $[F(1,22)=9.45, p<.01]$, blocks $[F(4,88)$ $=29.35, p<.001]$, and groups $\times$ blocks $[F(4,88)=$ $6.05, p<.001]$. Subsequent Newman-Keuls tests indicated that, from Block 1 to Block 5 , the activity scores decreased significantly for the NI subgroups $(p<.01)$ and the DI subgroups $(p<.05)$. It was also found that both DI subgroups showed significantly $(p<.01)$ less activity than the NI subgroups across all blocks. Finally,

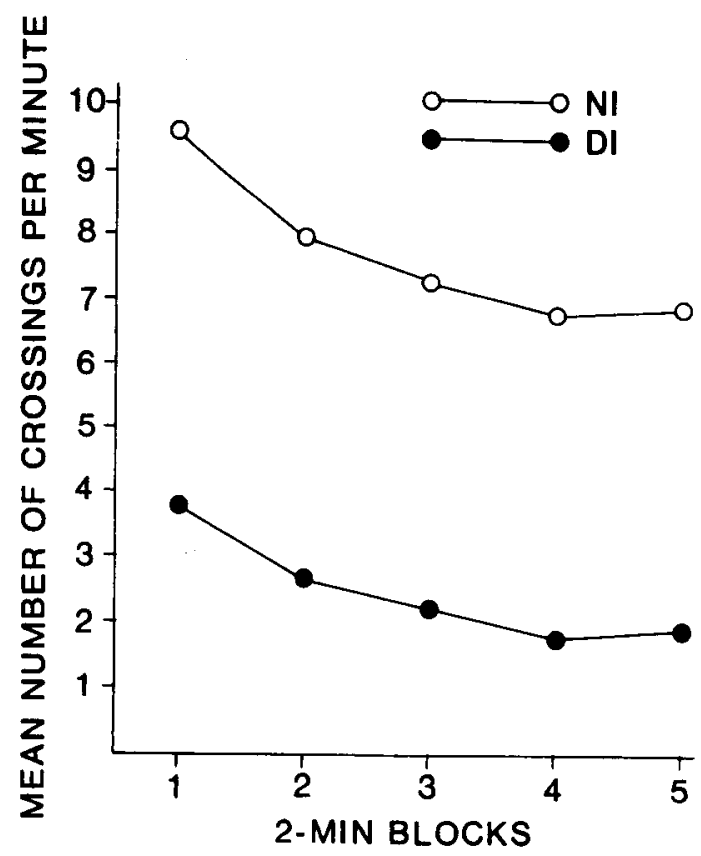

Figure 2. Mean number of grid crossings per minute over successive 2-min blocks for rats that were given 25 sessions of defeat (Group DI) or nondefeat (Group NI) experience as colony intruders.

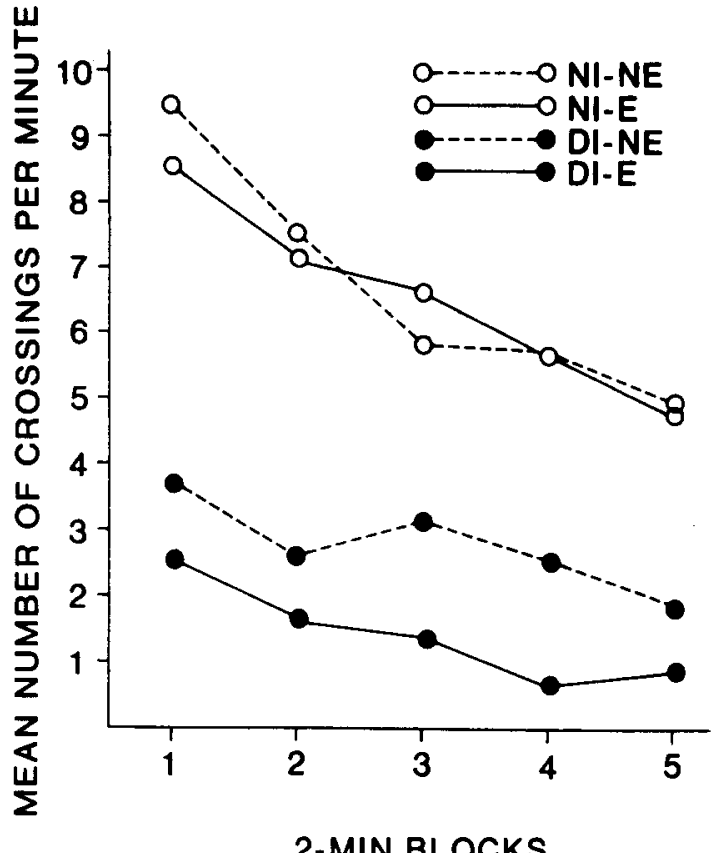

Figure 3. Mean number of grid crossings per minute over successive 2-min blocks for rats that were given 25 sessions of resident-intruder experience and a previous open-field sctivity test. Subgroups of defeated and nondefeated intruders were given a brief exposure, without defeat, to an aggressive colony (Group DI-E and Group NI-E, respectively), whereas the remaining subgroups (Group DI-NE and Group NI-NE) were not given such exposures before being retested for activity.

although no significant difference was found between Groups NI-E and NI-NE, Group DI-E was less active $(p<.08)$ than Group DI-NE, across all blocks combined. Further post hoc tests disclosed significant differences between these groups for Block $1(p<.05)$ and Blocks 3 and 4 ( $p$ s $<.01$ ).

Figure 4 presents the response latencies for Groups DI and NI during the shuttlebox-escape training that was given $24 \mathrm{~h}$ after their final exposure to a colony. The two groups rapidly acquired the escape response during the initial block of 5 FR 1 trials, with the mean number of escape responses and the mean escape-response latencies for both of these groups being virtually identical. The results from the FR 2 escape trials are of primary importance in assessing the rat's capacity for escape learning. During these 25 trials, Group NI had a mean of 18.58 escape responses, and this differed significantly from the mean of 6.58 escape responses for Group DI $[t(22)=$ $6.18, p<.001$, one-tailed test]. Figure 4 reveals that, during the FR 2 trials, Group DI showed virtually no changes in response latencies across the 5 blocks of trials, whereas Group NI displayed shorter latencies during the initial block of trials and continued to escape more rapidly across subsequent blocks. These observations were statistically confirmed by the results of a two-way, mixed ANOVA that indicated the following effects to be significant: groups $[F(1,22)=30.94, p<.001]$, blocks 


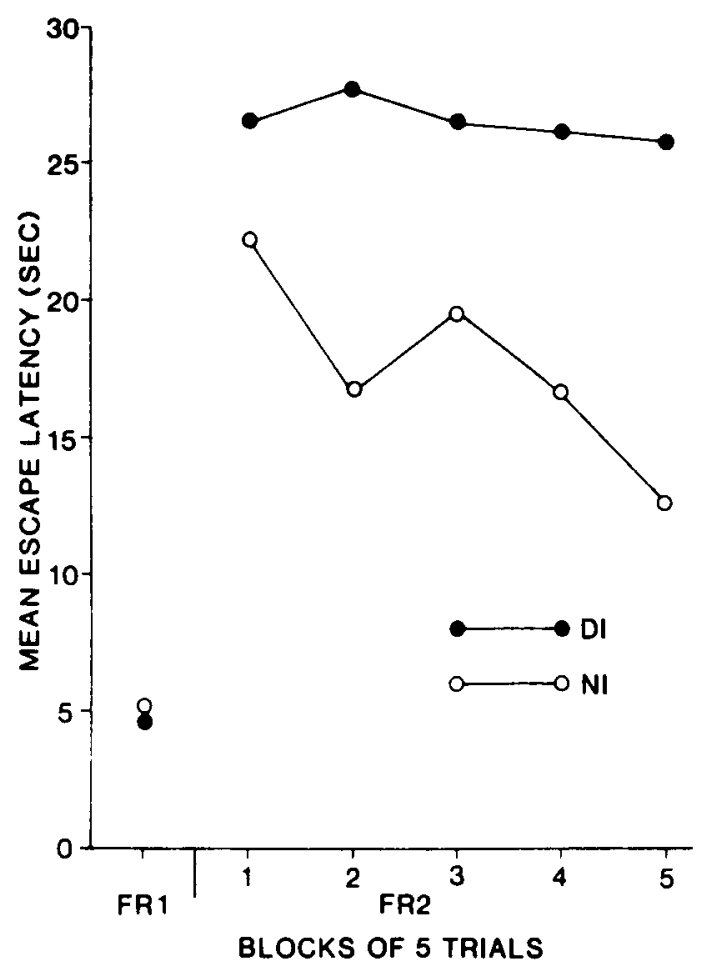

Figure 4. Mean shuttlebox-escape latencies (in seconds) for defented intruders (Group DI) and nondefeated intruders (Group NI) during five single-crossing (FR 1) trials and subsequent blocks of five double-crossing (FR 2) escape trials.

$[F(4,88)=5.67, p<.001]$, and groups $\times$ blocks $[F(4,88)=4.83, p<.01]$. Newman-Keuls tests indicated that the latencies of Group NI were significantly faster than those of Group DI on Block $2(p<.05)$ and on Block 3 through Block 6 (all $p s<.01$ ). Furthermore, Newman-Keuls tests revealed that, although the escape latencies of Group DI did not change across blocks of trials, Group NI showed significant $(p s<.01)$ decrements in escape latencies from Block 2 to Blocks 3, 5, and 6. The mean latencies for Group NI on Blocks 4, 5, and 6 were also significantly $(p s<.05$ ) different from each other, with a downward trend that reflects successful escape learning.

Pearson correlation tests were conducted to examine the possible relationships among measures, within each group, that might be of theoretical interest. In Group DI, significant negative correlations were found for the defeattime scores and a number of other measures: body weight at the end of resident-intruder testing $[r(10)=-.66$, $p<.01$, activity scores obtained immediately after a colony defeat $[r(10)=-.65, p<.01]$, and activity scores obtained $24 \mathrm{~h}$ after defeat, combined over exposure- versus nonexposure-to-colony conditions prior to testing $[r(10)=-.56, p<.05]$. Significant positive correlations, within Group DI, were found between body weight at the end of resident-intruder testing and the following measures: activity immediately after defeat $[r(10)$ $=.49, p<.05]$ and activity $24 \mathrm{~h}$ after defeat $[r(10)=$ $.63, p<.01]$. However, none of the reported correla- tions between the various measures for Group DI were found to be significantly correlated for Group NI (i.e., all $p s>.10]$.

\section{DISCUSSION}

A number of studies have reported findings for rats and mice that are similar to those of this experiment in showing that, compared with control animals, rats that are exposed to repeated defeat show an increment in defensive and/or submissive responses (e.g., Frischknecht et al., 1982; Kulling et al., 1987; Seward, 1946) and a reduction in body weight (Adams \& Boice, 1983; Luciano \& Lore, 1975; Raab et al., 1986; Thor \& Flannelly, 1976). The results of the present study also indicate that the amount of time that was engaged in defensive behavior is negatively correlated with the amount of weight that was gained by the defeated rats, which suggests that intruder defeat is a stressful event that has both behavioral and physiological consequences. However, with repeated sessions, defeat was found to result in an increase in the number of bites that the intruders received. This finding does not support the claim that defensive behavior enables intruders or subordinant colony animals to defend themselves against the bites of alpha rats (Burg \& Slotnick, 1983; Flannelly, Flannelly, \& Blanchard, 1984). One reason why intruder defense may not have attentuated alpha aggression and reduced the frequency of biting is that the alpha rats in this study were selected because of their previous display of asymptotic levels of aggression. In fact, many of these alpha residents would burrow in the bedding underneath the submissive intruder to gain access to its back, which was the primary target site for bites.

More importantly, the findings of the postencounter tests clearly indicate that repeated defeat, as opposed to nondefeat, experience produces emotional, physiological, and behavioral effects that are similar to those induced by repeated presentations on inescapable shock. For example, the increase in submissive behavior and in the number of bites that were received by intruders following repeated defeat replicates the reported changes in agonistic behavior that result from prior exposure to inescapable shocks (Williams \& Lierle, 1986). Furthermore, reduced long-term gains in body weight as a result of conspecific defeat have also been observed in rats exposed to repeated sessions of inescapable-shock, relative escapable-shock and no-shock, treatments (Weiss, 1968; Weiss et al., 1981).

The results of the open-field activity test, both immediately and $24 \mathrm{~h}$ after the series of resident-intruder sessions, indicate that defeat experience, relative to a nonaggressive interaction, produced a significant decrease in locomotion. A reduction in activity immediately following defeat has also been reported by other investigators (e.g., Raab et al., 1986). It should be recalled that all subjects in the present study were tested for activity with the soiled bedding of the alpha rats distributed on the floor 
of the open-field apparatus. Recently, our defensiveburying research has demonstrated that the presence of alpha odors in the bedding material during testing is critical in producing a suppression of prod burying and an increment in freezing in rats that had been given one session of defeat experience, as opposed to those without defeat experience (Williams \& Scott, 1988). Similarly, the presence of alpha odors in the present experiment did not disrupt the exploratory activity of subjects that had had prior intruder experience with nonaggressive colony residents. In fact, their level of activity was comparable to that previously observed for naive rats tested in this open-field apparatus without conspecific odors.

The decrement in locomotion in the open-field test $24 \mathrm{~h}$ following the last defeat session is consistent with several learned-helplessness studies that have found a long-term suppression in activity (Drugan \& Maier, 1982) and specific forms of exploratory activity (Bruto \& Anisman, 1983) after a session of inescapable shocks. Although none of these studies explicitly tested subjects in the context of fear-related odors, the odors from previously shocked conspecifics may have been present. Recently, research from our lab has shown that the odors of shocked donor rats function as mediating stimuli that potentiate freezing and disrupt prod burying in rats that had been given a session of inescapable shock $24 \mathrm{~h}$ prior to testing (Williams, 1987b). Another similarity between the effects of defeat and shock as stressors is that their long-term effects are augmented when some type of priming event is given to reinstate the stressful situation. In the case of exposure to inescapable shock, most studies have involved the administration of a few brief shocks immediately before the test session (Jackson et al., 1979; Maier \& Jackson, 1979). Similarly, in the present study, the observed suppression in activity $24 \mathrm{~h}$ after defeat was found to be augmented when our subjects were given a brief exposure to an alpha colony immediately before testing. The effectiveness of this type of priming is particularly interesting because (1) it suppressed the activity of previously defeated intruders but not of the nondefeated intruders, and (2) it evoked fear based on the alpha rat's attack without the experience of pain that results from being bitten. Further research on the effects of fear versus pain, in terms of learned and unlearned responses, is currently being conducted in our laboratory.

The results from the shuttlebox-escape phase of the present study demonstrate that the prior defeat of an intruder has no effect on escape performance involving a simple FR 1 single-crossing response. However, prior defeat did result in a subsequent deficit in performance and the complete failure to learn an FR 2 shuttling response. This finding replicates a portion of a study reported by Minor and Williams (1988) that involved far fewer sessions of defeat and less aggressive residents (i.e., less frequent bites received by the intruders). Therefore, repeated conspecific defeat, like inescapable shock and other laboratory stressors (e.g., cold-water swim, prolonged periods of restraint), clearly interferes with the subsequent learning of an instrumental response. Maier and his colleagues have recently argued that many of the shock-induced learned-helplessness studies that demonstrate an interference in shuttlebox-escape learning, are indicative of a disruption in performance or activity, as opposed to cognitive processing (Maier et al., 1983). According to these researchers, a deficit in cognition (e.g., association learning of response-outcome contingencies) can be assessed only by testing previously stressed and nonstressed subjects, using a discrimination or responsechoice task, in which the number of reinforced trials is identical for all subjects (Jackson et al., 1980; Maier et al., 1983). We agree with Maier's views, and postulate that the observed disruption in shuttlebox performance is primarily the result of motivational and/or emotional alteration that, in turn, influences a variety of psychological processes via numerous physiological mechanisms (see Maier \& Seligman, 1976; Szostak \& Anisman, 1985; Weiss et al., 1981; and Williams, 1987a, for further discussion of this issue).

Prior exposure to a series of inescapable, but not escapable, shocks has been found to produce a nonopioid analgesic reaction in rats if they are given tail-flick tests immediately after the shock session (Maier, Drugan, \& Grau, 1982), and an opioid reaction if tested $24 \mathrm{~h}$ later with a brief series of priming shocks (Jackson et al., 1979). Furthermore, the classical conditioning of a longterm opioid reaction in rats has been shown to occur in response to environmental or contextual cues, using the helplessness preshock procedure and tail-flick tests of analgesia (MacLennan, Jackson, \& Maier, 1980). However, the results of tail-flick testing in the present experiment, during baseline and immediately after 12 and 24 sessions of defeat versus nondefeat, failed to reveal any evidence of an analgesic reaction, even when alpha odors were present. Although an analgesic reaction to conspecific defeat might be observed using other testing procedures (e.g., forepaw licking following a formalin injection; Fanselow, 1986), our data are clearly not consistent with the helplessness research that has traditionally used tail-flick tests of analgesia. Furthermore, the present data are not in agreement with the reported analgesic tail-flick reactions that follow conspecific defeat, using other species and resident-intruder procedures. Male mice have been found to show analgesia, which is naloxone-reversible and cross-tolerant with morphine, after repeated exposure to agonistic defeat as colony intruders (Miczek et al., 1982, 1986; Rodgers \& Randall, 1986b). It has also been reported that mice show a nonopioid analgesic reaction immediately following a single encounter with an aggressive resident (Rodgers \& Randall, 1986a) or to the scent of a dominant mouse (Rodgers \& Randall, 1986c). In addition, Rodgers and his colleagues have recently reported that an analgesic tail-flick reaction, which is partially blocked by naloxone, occurs in male rats after they have been attacked by a lactating female with her pups (Rodgers, Hendrie, \& Waters, 1983). According to these investigators, this type of intruder- 
defeat experience is somewhat similar to resident-intruder tests with mice, in that lactating rats do not display a ritualized form of alpha attack before biting the intruder. Therefore, Rodgers views defeat by lactating conspecifics, in mice or rats, as an example of an unpredictable, and uncontrollable, aversive experience, while rat intruders, by showing defensive or submissive postures, have some degree of control over being attacked in an encounter with an alpha male (Rodgers \& Hendrie, 1984; Rodgers et al., 1983). At first glance, the present findings do not appear to be consistent with this interpretation, because the increase in defensive responses shown by our intruders was not an effective deterrent against alpha attack. However, defense may reduce the intensity or change the topography of the attack to the point that controllability and/or predictability are achieved. Thus, the rat would not have to rely on an analgesic reaction to function as its only coping mechanism.

The results of this experiment definitely suggest that the consequences of repeated defeat by a dominant conspecific have a number of similarities with the behavioral and physiological effects previously reported in learnedhelplessness studies involving shock as a stressor. According to the senior author's SCFD theory, repeated exposures to any stressor, without the response feedback associated with the termination of such a stimulus, results in the classical conditioning of fear to such contextual or situational cues as conspecific stress or alpha odors (Willimas, 1987a, 1987b; Williams \& Lierle, 1986). This contextual potentiation of fear is also assumed to activate a motivational system (Adams, 1980) that is responsible for the increase in defensive types of responses to the exclusion of other learned and unlearned behaviors.

While the present results demonstrate that shock and repeated defeat produce similar helplessness effects, this experiment was not designed to examine whether contextual stress odors at the time of testing were critical, in terms of producing these effects. As mentioned previously, all tests of analgesia, exploratory behavior, and escape learning in this experiment were conducted with alpha odors present. This was done because our recent research had shown that biologically relevant stress odors significantly augmented alterations in learned and unlearned responses in tests of defensvie burying and freezing following a single session of alpha defeat (Williams \& Scott, 1988) or inescapable shock (Williams, 1987b). To demonstrate the importance and the specificity of the alpha odors with regard to the present testing procedures, a factorial-design experiment is currently being performed with both defeated and nondefeated intruders that are to be tested later in the presence of the odors of either alpha or nonalpha rats. We hope that the results of this research will determine whether the reported group differences in exploration and escape learning are due to the disruptive properties of the odors, the residual effects of the repeated expousre to defeat, or a combination of these factors.

\section{REFERENCES}

AD^ms, D. B. (1980). Motivational systems of agonistic behavior in muroid rodents: A comparative review and neural model. Aggressive Behavior, 6, 295-346.

ADAmS, N., BoICE, R. (1983). A longitudinal study of dominance in an outdoor colony of domestic rats. Journal of Comparative Psychology, 97, 24-33.

Anisman, H., KokKInidis, L., \& SkLAR, L. S. (1982). Contribution of neurochemical change to stress induced behavioral deficits. In $\mathrm{S}$. J. Cooper (Ed.), Theory in psychopharmacology (Vol. 1, pp. 65-102). London: Academic Press.

Anisman, H., Suissa, A., Sklar, L. S. (1980). Escape deficits induced by uncontrollable stress: Antagonism by norepinephrine and dopamine agonists. Behavioral \& Neural Biology, 28, 34-47.

BrUTo, V., \& ANisman, H. (1983). Alteration of exploratory patterns induced by uncontrollable shock. Behavioral \& Neural Biology, 37 , 302-316.

BURG, R. D., SLotnick, B. M. (1983). Response of colony mice to intruders with different fighting experience. Aggressive Behavior, 9, 49-58.

Desiderato, O., Newman, A. (1971). Conditioned suppression produced in rats by tones paired with escapable or inescapable shock. Journal of Comparative \& Physiological Psychology, 77, 427-431.

Drugan, R. C., \& MaIER, S. F. (1982). The nature of the activity deficit produced by inescapable shock. Animal Learning \& Behavior, 10 , 401-406.

FANSELOW, M. S. (1986). Conditioned fear-induced opiate analgesia: A competing motivatonal state theory of analgesia. Annals of the New York Academy of Sciences, 467, 40-54.

Flannelly, K. H., FlanNelly, L., \& Blanchard, R. J. (1984). Adult experience and expression of aggression: A comparative analysis. In K. J. Flannelly, R. J. Blanchard, \& D. C. Blanchard (Eds.), Biological perspectives on aggression (pp. 207-259). New York: Liss.

Frischknecht, H. R., Siegried, B., W WSER, P. G. (1982). Learning of submissive behavior in mice: A new model. Behavioural Processes, 7, 235-245.

JACKSON, R. L., AleXANDer, J. H., \& MAIER, S. F. (1980). Learned helplessness, inactivity and associative deficits: Effects of inescapable shock on response choice escape learning. Journal of Experimental Psychology: Animal Behavior Processes, 6, 1-20.

JaCkson, R. L., MAIER, S. F., \& CoON, D. J. (1979). Long-term analgesic effects of inescapable shock and learned helplessness. Science, 206, 91-94.

KAHN, M. W. (1951). The effect of severe defeat at various age levels on the aggressive behavior of mice. Journal of Genetic Psychology, 79, 117-130.

Kulling, P., Frischknecht, H. R., Pasi, A., Waser, P. G., \& SiegFRIED, B. (1987). Effects of repeated as compared to single aggressive confrontation on nociception and defense behavior in C57BL/6 and DBA/2mice. Physiology \& Behavior, 39, 599-605.

LAGersPetz, K. M. J., \& SANDNABbA, K. (1982). The decline of aggressiveness in male mice during group caging as determined by punishment delivered by the cage mates. Aggressive Behavior, 8, 319-328.

LuCIANO, D., \& LORE, R. (1975). Aggression and social experience in domestic rats. Joumal of Comparative \& Physiological Psychology, 88, 917-923.

Maclennan, A. J., Jackson, R. L., \& Maier, S. F. (1980). Conditioned analgesia in the rat. Bulletin of the Psychonomic Society, 15, 387-390.

Maier, S. F., Anderson, C., \& Lieberman, D. A. (1972). Influences of control of shock on subsequent shock-elicited aggression. Journal of Comparative \& Physiological Psychology, 81, 94-100.

Maier, S. F., CoOn, D. J., MCDANiel, M. A., JAckson, R. L., \& GRAU, J. (1979). The time course of learned helplessness, inactivity, and nociceptive deficits in rats. Learning \& Motivation, 10, 467-487.

Maier, S. F., Drugan, R. C., \& GraU, J. W. (1982). Controllabil- 
ity, coping behavior, and stress-induced analgesia in the rat. Pain, 12, 47-56.

Maier, S. F., Drugan, R., Grau, J. W., Hyson, R., Maclennan, A. J., Moye, T., Madden, J., \& Barchas, J. D. (1983). Learned helplessness, pain inhibition and the endogenous opiates. In M. D. Zeiler \& P. Harzem (Eds.), Advances in animal behavior (Vol. 3, pp. 275-323). New York: Wiley.

MAIER, S. F., \& JACKSON, R. L. (1979). Learned helplessness: All of us were right (and wrong): Inescapable shock has multiple effects. In G. Bower (Ed.), The psychology of learning and motivation (Vol. 3 pp. 155-218). New York: Academic Press.

MaIer, S. F., Selugman, M. E. P. (1976). Leamed helplessness: Theory and evidence. Joumal of Experimental Psychology: General, 105, 3-46.

MCAluister, K. H., Berry, M. S., \& Brain, P. F. (1985). Substrate soiled by unfamiliar conspecific modifies opioid activity in mice placed in novel environments. Physiology \& Behavior, 35, 465-471.

Miczek, K. A., Thompson, M. L., Shuster, L. (1982). Opioidlike analgesia in defeated mice. Science, 215, 1520-1522.

MiczeK, K. A., Thompson, M. L., \& Shuster, L. (1986). Analgesia following defeat in an aggressive encounter: Development of tolerance and changes in opiod receptors. Annals of the New York Academy of Sciences, 467, 14-29.

MineKa, S., CoOK, M., \& Miller, S. (1984). Fear conditioned with escapable and inescapable shock: Effects of a feedback stimulus. Journal of Experimental Psychology: Animal Behavior Processes, 10, 307-323.

MinOR, T. R., \& LoLORDo, V. M. (1984). Escape deficits following inescapable shock: The role of contextual odor. Journal of Experimental Psychology: Animal Behavior Processes, 10, 168-181.

Minor, T. R., \& Williams, J. L. (1988). Social stress, dominance, and "learned helplessness": SAP hypothesis. Manuscript submitted for publication.

RaAb, A., Dantzer, R., Michaud, B., Mormede, P., Taghzouti, K., Simon, H., \& Le MoAl, M. (1986). Behavioural, physiological and immunological consequences of social status and aggression in chronically coexisting resident-intruder dyads of male rats. Physiology \& Behavior, 36, 223-228.

Rodgers, R. J., \& HeNDRIE, C. A. (1982). Agonistic behaviour in rats: Evidence for non-involvement of opioid mechanisms. Physiology \& Behavior, 29, 85-90.

RodGers, R. J., \& Hendrie, C. A. (1984). Encounter-induced antinociception: Evidence and speculation. Academic Psychology Bulletin, 6, 259-270.

Rodgers, R. J., Hendrie, C. A., \& Waters, A. J. (1983). Naloxone partially antagonizes post-encounter analgesia and enhances defensive responding in male rats exposed to attack from lactating conspecifics. Physiology \& Behavior, 30, 781-788.

RoDGERS, R. J., \& RANDALL, J. I. (1986a). Acute non-opiod analgesia in defeated male mice. Physiology \& Behavior, 36, 947-950.
Rodgers, R. J., \& RANDall, J. I. (1986b). Extended attack from a resident conspecfic is critical to the development of long-lasting analgesia in male intruder mice. Physiology \& Behavior, 38, 427-430.

Rodgers, R. J., \& RANDall, J. I. (1986c). Resident's scent: A critical factor in acute analgesia reaction to defeat experience in male mice. Physiology \& Behavior, 37, 317-322.

Rosellini, R. A. (1978). Inescapable shock interferes with the acquisition of an appetitive operant. Animal Learning \& Behavior, 6, 155-159.

Rosellini, R. A., DeCola, J. P., a Shapiro, N. R. (1982). Crossmotivational effects of inescapable shock are associative in nature. Journal of Experimental Psychology: Animal Behavior Processes, 8 376-388.

SEWARD, J. P. (1946). Aggressive behavior in the rat: IV. Submission as determined by conditioning, extinction, and disuse. Joumal of Comparative Psychology, 39, 51-78.

Szostak, C., \& ANisman, H. (1985). Stimulus perseveration in a water maze following exposure to controllable and uncontrollable shock. Behavioral \& Neural Biology, 43, 178-198.

THOR, D. H., \& FLANNELLY, K. (1976). Intruder gonadectomy and elicitation of territorial aggression in the rat. Physiology \& Behavior, 17, 725-727.

WEISs, J. M. (1968). Effects of coping responses on stress. Journal of Comparative \& Physiological Psychology, 65, 251-260.

Weiss, J., Goodman, P., Losito, B., Corrigan, S., Charry, J., \& BAILEY, W. (1981). Behavioral depression produced by an uncontrollable stressor: Relationship to norepinephrine, dopamine, and serotonin levels in various regions of rat brain. Brain Research Review, 3, 167-205.

WiLliams, J. L. (1982). Influence of shock controllability by dominant rats on subsequent attack and defensive behaviors toward colony intruders. Animal Learning \& Behavior, 10, 305-313.

WILLiams, J. L. (1984). Influence of postpartum shock controllability on subsequent maternal behavior in rats. Animal Leaming \& Behavior, 12, 209-216.

WiLuAMs, J. L. (1987a). Effects of shock controllability on alpha male aggression and defense, defeat of intruders, and defensive burying. Psychological Record, 37, 381-386.

WILLIAMS, J. L. (1987b). Influence of conspecific stress odors and shock controllability on conditioned defeensive burying. Animal Learning \& Behavior, 15, 333-341.

Williams, J. L., \& LierLe, D. M. (1986). Effects of stress controllability, immunizaton, and therapy of the subsequent defeat of colony intruders. Animal Learning \& Behavior, 14, 305-314.

WiLlams, J. L., \& ScotT, D. K. (1988). Influence of defeat and alpha resident odors on subsequent defensive burying and freezing. Manuscript submitted for publication.

(Manuscript received September 22, 1987; revision accepted for publication March 1, 1988.) 